\title{
Comportamento forrageiro de formigas cortadeiras Atta sexdens piriventris Santschi, 1919, em ambiente de Campos de Altitude no Sul do Brasil
}

\author{
Foraging behavior of leaf-cutting ants Atta sexdens piriventris Santschi, 1919, in an High-altitude \\ grasslands environment in southern Brazil
}

Comportamiento forrajeador de las hormigas cortadoras de hojas Atta sexdens piriventris Santschi, 1919, en un ambiente de Campos de Altitud en el sur de Brasil

Recebido: 09/03/2021 | Revisado: 16/03/2021 | Aceito: 24/03/2021 | Publicado: 31/03/2021

Alexandre Giesel
ORCID: https://orcid.org/0000-0002-9569-015X
Federal University of Technology - Paraná, Brasil
E-mail: alexandergiesel@ gmail.com
Mari Inês Carissimi Boff
ORCID: https://orcid.org/0000-0003-1700-8837
State University of Santa Catarina, Brasil
E-mail: mari.boff@udesc.br
Patricia Fernandes
ORCID: https://orcid.org/0000-0002-0981-5930
Federal University of Technology - Paraná, Brasil
E-mail: patriciaf@ @utfpr.edu.br
Pedro Boff
ORCID: https://orcid.org/0000-0002-9041-5503
E-mail: boff.pedro@ yahoo.com.br

\section{Resumo}

Na Microrregião dos Campos de Lages, Santa Catarina, as condições edafoclímaticas, associadas à vegetação típica desta região podem particularizar o comportamento forrageiro de formigas cortadeiras Atta sexdens piriventris, diferentemente das já relatadas para outros locais. Este trabalho teve por objetivo a estudar a bioecologia de forrageamento A. sexdens piriventris que ocorrem naturalmente na Microrregião dos Campos de Lages. Desta forma, formigueiros da espécie $A$. sexdens piriventris foram localizados de forma aleatória, através de características morfológicas dos indivíduos, e da aparência com aspecto de terra lavrada superficial dos formigueiros. Em cada formigueiro selecionado, foi realizado o levantamento das espécies vegetais preferidas para o forrageamento. Amostras das espécies vegetais, ou partes vegetativas forrageadas foram herborizadas e posteriormente classificadas e identificadas. As características edafoclimáticas da Microrregião dos Campos de Lages, particularizam o comportamento forrageiro e de nidificação apresentado por formigas cortadeiras A. sexdens piriventris. Foram identificadas 68 espécies de plantas distribuídas em 27 famílias botânicas, dentre as utilizadas para o forrageio. Plantas das famílias Poaceae e Asteraceae foram as mais utilizadas no forrageamento por formigas A. sexdens piriventris, sendo a espécie Baccharis trimera (Asteraceae) a mais forrageada. Formigueiros A. sexdens piriventris estavam presentes preferencialmente em área de borda de ambientes.

Palavras-chave: Comportamento; Forrageamento; Formigas; Campos de altitude.

\begin{abstract}
In the Microregion of Campos de Lages, Santa Catarina, the edaphoclimate conditions, associated with the typical vegetation of this region may particularize the foraging behavior of leaf-cutting ants Atta sexdens piriventris, unlike those already reported for other locations. This work aimed to study the bio-ecology of foraging A. sexdens piriventris naturally occurring in the Microregion of Campos de Lages. Thus, anthills of the species A. sexdens piriventris were randomly located, through morphological characteristics of the individuals, and the appearance with the appearance of superficial tilled soil of the anthills. In each selected anthill, a survey of the preferred plant species for foraging was carried out. Samples of the foraged plant species or vegetative parts were herborized and later classified and identified. The edaphoclimatic characteristics of the Campos de Lages Microregion, particularize the foraging and nesting behavior presented by leaf-cutting ants A. sexdens piriventris. 68 species of plants were identified, distributed in 27 botanical families, among those used for foraging. Plants from the Poaceae and Asteraceae families were the most used in the foraging by ants A. sexdens piriventris, with Baccharis trimera (Asteraceae) being the most foraged. Anthilles A. sexdens piriventris were present preferentially in the edge area of environments.
\end{abstract}

Keywords: Behaviour; Foraging; Ants; High-altitude grasslands. 


\begin{abstract}
Resumen
En la microrregión de Campos de Lages, Santa Catarina, las condiciones edafoclimáticas, asociadas a la vegetación típica de esta región, pueden particularizar el comportamiento de forrajeo de las hormigas cortadoras de hojas Atta sexdens piriventris, a diferencia de las ya reportadas para otras localidades. Este trabajo tuvo como objetivo estudiar la bioecología de A. sexdens piriventris que forrajea de forma natural en la microrregión de Campos de Lages. Así, los hormigueros de la especie $A$. sexdens piriventris fueron localizados al azar, a través de las características morfológicas de los individuos, y del aspecto con suelo labrado superficial de los hormigueros. En cada hormiguero seleccionado se realizó un estudio de las especies vegetales preferidas para forrajear. Las muestras de las especies vegetales forrajeadas o las partes vegetativas se herborizaron y posteriormente se clasificaron e identificaron. Las características edafoclimáticas de la Microrregión Campos de Lages, particularizan el comportamiento de forrajeo y nidificación que presentan las hormigas cortadoras de hojas A. sexdens piriventris. Se identificaron 68 especies de plantas distribuidas en 27 familias botánicas, entre las que se utilizan para forrajeo. Las plantas de las familias Poaceae y Asteraceae fueron las más utilizadas en la búsqueda de alimento por las hormigas A. sexdens piriventris, siendo Baccharis trimera (Asteraceae) la más recolectada. Hormigueiros de A. sexdens piriventris estuvieron presentes preferentemente en el área de borde de los ambientes.
\end{abstract}

Palabras clave: Comportamiento; Forrajeo; Hormigas; Campos de altitud.

\title{
1. Introdução
}

A atividade de cortar e transportar o material forrageado distingue as formigas cortadeiras, como as únicas espécies de insetos que praticam uma agricultura, baseada na exploração de diferentes espécies vegetais, utilizadas como substrato para o cultivo de espécies de fungos (Farji-brener et al., 2018). A atividade de exploração de espécies vegetais, para o forrageio por formigas cortadeiras, envolve várias etapas, onde muitas ainda são desconhecidas pelo homem (Ferreira, 2020).

$\mathrm{Na}$ exploração do ambiente para a busca de materiais adequados, as formigas cortadeiras se deparam com uma infinidade de possibilidade de plantas, e embora, sejam seletivas durante o processo de escolha, as formigas cortadeiras são consideradas polífagas, pois aproveitam inúmeras espécies vegetais na atividade de forrageamento (Farji-brener et al., 2018). Este processo de forrageamento, realizado pelas formigas cortadeiras, envolve uma criteriosa seleção do material vegetativo, influenciada por inúmeros fatores, que variam desde as características morfológicas, nutricionais e principalmente a presença de compostos do metabolismo secundário existentes nas espécies vegetais forrageadas (Reed e Cherrett, 2019). Segundo Infante-Rodríguez et al. (2019) os metabolitos secundários influenciam diretamente a palatabilidade do material vegetativo, reduzindo a sua atratividade, podendo ainda ter ação tóxica direta sobre as formigas cortadeiras ou ao seu fungo simbionte. Cherrett (1972) enfatiza que as comunidades de plantas disponíveis para o forrageamento representam um mosaico de manchas de recursos palatáveis para as formigas cortadeiras, que variam em qualidade e quantidade ao longo do tempo.

A variação espacial e temporal das plantas selecionadas para o forrageio por formigas cortadeiras, também pode ser influenciada por fatores ambientais, principalmente aqueles de origem abiótica como a temperatura e a umidade (Giesel et al., 2020). A espécie de formiga cortadeira Acromyrmex subterraneus subterraneus Forel, 1893 respondeu às alterações de clima através da mudança no horário de início da atividade forrageira (Maciel et al., 1995). Em trabalho realizado por Araújo et al. (2018), com formigas da espécie Acromyrmex laticeps nigrosetosus Forel, 1908, o aumento da atividade forrageira ocorreu durante o período noturno. Estes mesmos autores observaram uma relação negativa entre a temperatura do ar e o fluxo de formigas nas trilhas de forrageamento, bem como, uma correlação positiva entre o percentual de umidade relativa do ar, e atividade forrageira de formigas cortadeiras. Tonhasca Jr. e Bragança (2000) verificaram que durante o dia, operárias da espécie A. sexdens sexdens, reduziram o forrageamento e que a atividade forrageira foi interrompida quando as temperaturas atingiram $30{ }^{\circ} \mathrm{C}$. Segundo Della Lucia et al. (2011) existe uma necessidade na ampliação de estudos relacionados a aspectos comportamentais de formigas cortadeiras em diferentes regiões, pois geram informações que podem auxiliar no manejo destes insetos nos diversos agroecossistemas existentes, devido às particularidades de cada região.

Este trabalho teve por objetivo estudar a influência de fatores abióticos (edafoclimáticos) sobre os hábitos e a sazonalidade de forrageamento de formigas cortadeiras das espécies A. sexdens piriventris Santschi, 1919, na Microrregião dos 
Campos de Lages, SC, Brasil.

\section{Metodologia}

a) local e desenvolvimento do estudo

O estudo foi realizado na Microrregião dos Campos de Lages, SC, a qual é composta por 18 municípios. (Figura 1).

Figura 1. Mapa geográfico da Microrregião dos Campos de Lages, SC.

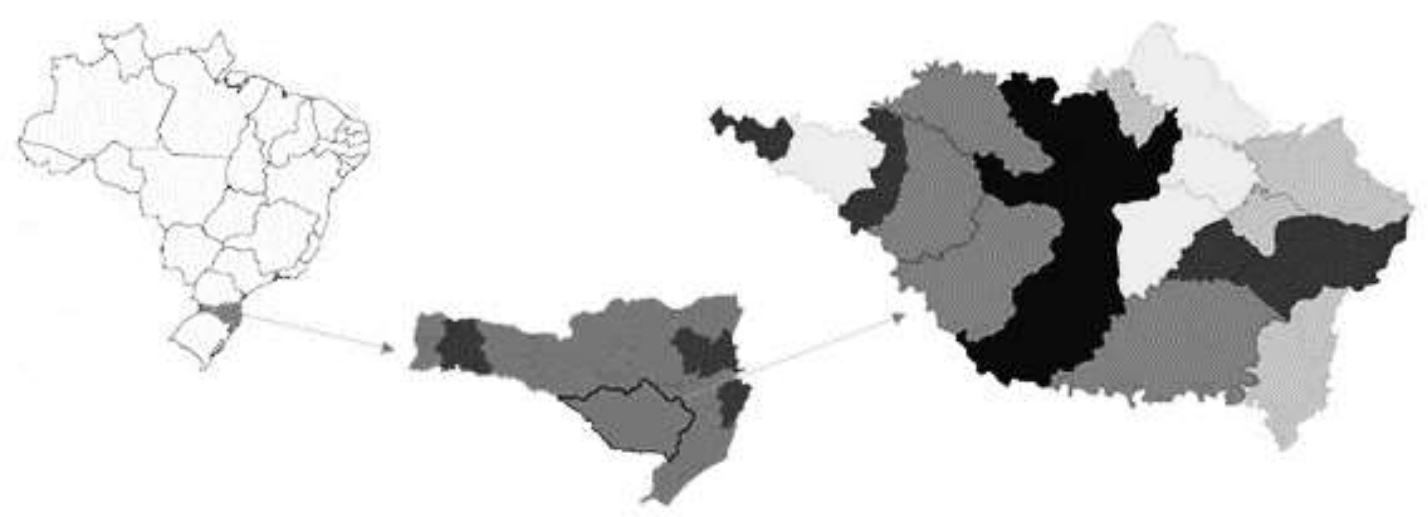

Fonte: Acervo da pesquisa.

O levantamento de espécies forrageadas por formigas cortadeiras A. sexdens piriventris, ocorreu no período de agosto de 2010 a dezembro de 2011, através da identificação de formigueiros selecionados ao acaso. Desta forma o número de formigueiros amostrados não foi determinado previamente, visto que a seleção dos mesmos ocorreu conforme as variações no gradiente ambiental de cada município pertencente a microrregião. No presente estudo entendeu-se por gradiente ambiental as variações de relevo e de vegetação existente em cada local amostrado.

No momento da seleção de formigueiros de A. sexdens piriventris, foi realizada a coleta de exemplares de indivíduos de cada formigueiro selecionado. Foram consideradas formigas pertencentes a espécie A. sexdens piriventris, indivíduos que apresentassem três pares de espinho no dorso, e formigueiros com aparência superficial de terra lavrada com montes de terra solta e com numerosas aberturas na superfície do solo, denominadas de olheiros.

Em cada formigueiro amostrado foi realizado o georreferenciamento através de GPS manual (Garmin Etrex®), e mensurado área de cada formigueiro através da avaliação do diâmetro maior pelo menor, com auxílio de fita métrica topográfica $(60 \mathrm{~m})$.

A coleta das formigas foi realizada por catação manual de, no mínimo, 100 formigas que transitavam nas trilhas dos respectivos formigueiros. Cada amostra foi individualizada em frasco de plástico com tampa contendo álcool (70\%) e encaminhadas para posterior identificação no Laboratório de Homeopatia e Saúde Vegetal da Estação Experimental da Empresa de Pesquisa Agropecuária e Extensão Rural de Santa Catarina do Município de Lages (EEpagri/Lages).

No momento da identificação da espécie de formigas cortadeiras foram selecionados indivíduos de maior tamanho. Para esta identificação, foram utilizadas as chaves sistemáticas propostas por Della Lucia et al. (2011), e chave sistemática ilustrada elaborada a partir de Loeck e Grutzmacher (2001). Amostras também foram encaminhas para de confirmação de espécies para professor especialista da Universidade Federal de Santa Maria (UFSM). Em cada formigueiro selecionado, foi realizado o levantamento das espécies vegetais preferidas para o forrageamento. Esta avaliação foi realizada em um ponto fixo, no final das duas trilhas mais ativas, na área conhecida por "área de forrageamento", fazendo-se a identificação das espécies 
vegetais que apresentavam indivíduos de formigas em atividade de forrageamento, cortando parte da planta. Este levantamento foi limitado a um raio de $20 \mathrm{~m}$ no entorno do ponto pré-determinado na respectiva área de forrageamento. Amostras das espécies vegetais forrageadas foram herborizadas e posteriormente identificadas. Para a identificação das espécies de plantas forrageadas, foi realizada a montagem de exsicatas, realizando-se a identificação segundo o sistema de classificação APG II (família, gênero e espécie). Para a identificação deste material, foram realizados registros fotográficos, consulta a especialistas, comparação com exemplares existentes no herbário da UDESC/CAV, material bibliográfico (Lorenzi, 1986; de Rudder, 2002; Lorenzi e Matos, 2008; Lorenzi, 2008; de OLiveira et al., 2011), e consulta a sites especializados como o Flora SBS e o Flora Digital do Rio Grande do Sul.

$\mathrm{Na}$ verificação da distribuição espacial das espécies de plantas forrageadas em relação à espécies de formigas, foi elaborada matriz florística de presença e ausência, e outra matriz com as coordenadas geográficas dos respetivos formigueiros pertencentes às espécies de formigas identificadas, aplicando-se o teste de Mantel (Felfili, 2011).

Também foi realizada a categorização dos locais de instalação dos formigueiros, que foram classificados como: a) campo nativo; b) fragmento florestal; c) lavoura; d) pastagem e e) outros (florestas plantadas, pomares e etc.). Considerou-se neste trabalho como fragmento florestal, áreas de vegetação natural, interrompidas por barreiras antrópicas ou naturais, de tamanho variável.

A caracterização ambiental do entorno dos formigueiros, foi analisada através da elaboração de uma matriz de presença e ausência, determinando-se o percentual de formigueiros para cada ocasião. Para a determinação das espécies vegetais forrageadas foi elaborada matriz de presença e ausência para determinação dos valores de frequência.

$\mathrm{Na}$ verificação da distribuição espacial das espécies de plantas forrageadas em relação a espécies de formigas, foi elaborada matriz florística de presença e ausência, e outra matriz com as coordenadas geográficas dos respetivos formigueiros pertencentes às espécies de formigas identificadas, aplicando-se o teste de Mantel (Felfili, 2011).

Para a realização das análises estatísticas foi utilizado o programa R (R Development Core Team, 2012).

A pesquisa se configura em uma abordagem quantitativa, em que os métodos utilizados auxiliam o pesquisador na interpretação do fenômeno investigado (Pereira et al. 2018), classificada como pesquisa de campo, com a intenção de provar, e descrever resultados obtidos pelo levantamento e coleta de informações que se relacionam ao objetivo de pesquisa deste trabalho.

\section{Resultados e Discussão}

Durante o trabalho de levantamento de espécies de formigas cortadeiras foram amostrados 17 pontos distribuídos pela Microrregião dos Campos de Lages, conforme a Figura 2. 
Figura 2. Distribuição dos formigueiros de Atta sexdens piriventris na Microrregião dos Campos de altitude de Lages, SC, Brasil, 2010/2011. Cada ponto é representado por um único formigueiro.

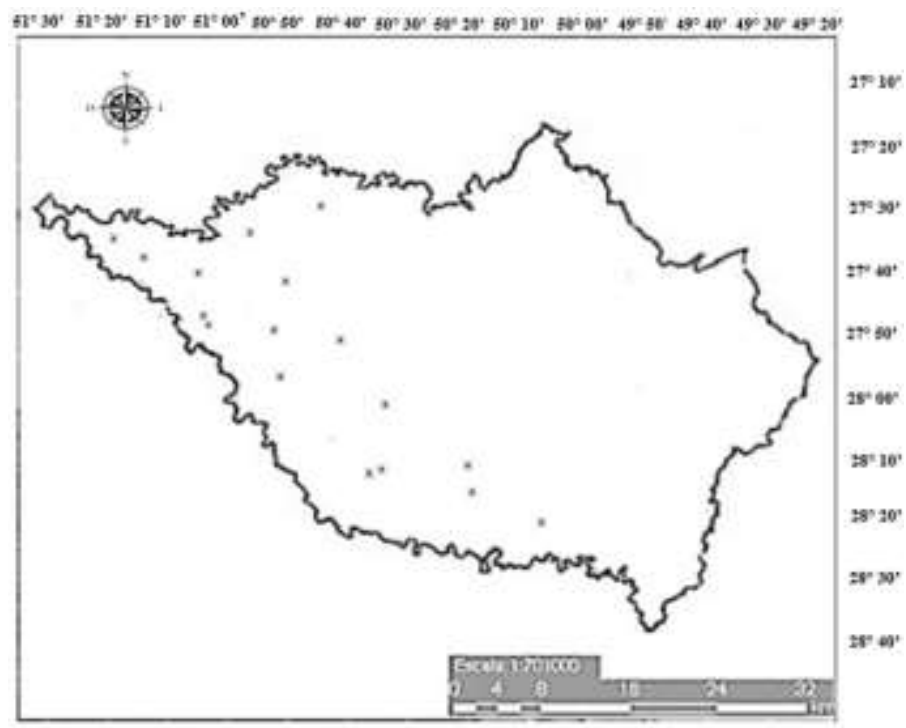

Fonte: Acervo da pesquisa.

As espécies de plantas preferidas para o forrageio por formigas das espécies A. sexdens piriventris na Microrregião dos Campos de Lages, estão descritas na Tabela 1. 
Tabela 1. Espécies de plantas forrageadas pela formiga cortadeira Atta sexdens piriventris na Microrregião dos Campos de Lages, SC, Brasil, 2010/2011.

\begin{tabular}{|c|c|c|c|}
\hline Família/Espécie & $\begin{array}{c}\text { Frequência de } \\
\text { forrageamento }\end{array}$ & Família/Espécie & $\begin{array}{l}\text { Frequência de } \\
\text { forrageamento }\end{array}$ \\
\hline AMARANTHACEAE & & MELIACEAE & \\
\hline Chenopodium ambrosioides (L.) & $1 *$ & Cabralea canjerana (Vell.) & 1 \\
\hline ASTERACEAE & & MORACEAE & \\
\hline Acanthospermum australe (Kuntze) & 1 & Morus sp. & 5 \\
\hline Ageratum conyzoides $(\mathrm{L})$. & 1 & & \\
\hline Artemisia verlotorum (Lamotte) & 2 & MYRTACEAE & \\
\hline Baccharis trimera (Less) DC. & 10 & Myrcia splendens (Sw.) & 1 \\
\hline Bidens pilosa $(\mathrm{L})$. & 2 & $\begin{array}{l}\text { Campomanesia xanthocarpa } \\
\text { (O.Berg) }\end{array}$ & 2 \\
\hline Emilia sonchifolia (L.) & 1 & Myrcia oblongata (DC.) & 1 \\
\hline Erechtites hieracifolia (Rafin.) & 2 & Eucalyptus sp. & 3 \\
\hline Erigeron bonariensis $(\mathrm{L})$. & 1 & $\begin{array}{l}\text { Calyptranthes grandifolia } \\
\text { (O.Berg) }\end{array}$ & 1 \\
\hline Galinsoga parviflora $(\mathrm{Cav})$ & 1 & Eugenia spp. & 4 \\
\hline Parthenium hysterophorus (L.) & 1 & & \\
\hline Senecio brasiliensis (Less) & 1 & PHYLLANTHACEAE & \\
\hline Soliva pterosperma (Juss.) & 1 & Leonotis nepetifolia (L.) & 1 \\
\hline Sonchus oleraceus (L.) & 2 & Phyllanthus corcovadensis (L.) & 1 \\
\hline Taraxacum officinale (Wiggers) & 1 & & \\
\hline \multirow[t]{2}{*}{ Xanthium strumarium (L.) } & 1 & POACEAE & \\
\hline & & Agrostis montevidensis (Spreng) & 3 \\
\hline AQUIFOLIACEAE & & Aristida ssp. & 1 \\
\hline \multirow[t]{2}{*}{ Ilex theaezans (Mart.) } & 1 & Axonopus barbigerus (Kunth.) & 1 \\
\hline & & Bromus sp. & 2 \\
\hline BRASSICACEAE & & $\begin{array}{l}\text { Calamagrostis viridiflavescens } \\
\text { (Poir.) }\end{array}$ & 1 \\
\hline \multirow[t]{2}{*}{ Lepidium pseudodidymum (Thell) } & 2 & Echinochloa ssp. & 3 \\
\hline & & Panicum ssp. & 4 \\
\hline CANELLACEAE & & $\begin{array}{l}\text { Pennisetum clandestinum } \\
\text { (Hochst) }\end{array}$ & 1 \\
\hline \multirow[t]{2}{*}{ Capsicodendron dinisii (Schwancke) } & 1 & Pоа аппиа $(\mathrm{L})$. & 3 \\
\hline & & Lolium multiflorum (Lam) & 2 \\
\hline CLETHRACEAE & & Sorghastrum pellitum (Parodi) & 1 \\
\hline \multirow{2}{*}{ Clethra scabra (Pers.) } & 1 & Sporobolus indicus (L.) & 1 \\
\hline & & Trachypogon spicatus (L. F.) & 1 \\
\hline \multicolumn{4}{|l|}{ COMMELINACEAE } \\
\hline \multirow[t]{2}{*}{ Commelina benghalensis (L.) } & 2 & POLYGONACEAE & \\
\hline & & Rumex obtusifolius (L.) & 5 \\
\hline CONVOLVULACEAE & & Portulaca oleracea (L.) & 2 \\
\hline \multirow[t]{2}{*}{ Ipomoea sp. } & 2 & & \\
\hline & & PROTEACEAE & \\
\hline CUPRESSACEAE & & Roupala brasiliensis (Klotzsch) & 1 \\
\hline \multirow[t]{2}{*}{ Cupressus lusitanica (Miller) } & 1 & & \\
\hline & & PINACEAE & \\
\hline EUPHORBIACEAE & & Pinus elliotii (Engelm) & 3 \\
\hline Euphorbia sp. & 2 & & \\
\hline \multirow[t]{2}{*}{ Ricinus communis $(\mathrm{L})}$. & 1 & ROSACEAE & \\
\hline & & Malus domestica (Borkh) & 2 \\
\hline FABACEAE & & Prunus persica $(\mathrm{L})$. & 1 \\
\hline Casia ocidentalis (L.) & 2 & Pyrus sp. & 2 \\
\hline Inga sessilis (Mart.) & 2 & & \\
\hline Trifolium pratense $(\mathrm{L})$. & & SALICACEAE & \\
\hline Mimosa scabrella (Benth) & 3 & Casearia decandra (Jacq.) & 1 \\
\hline FABOIDEAE & & SAPINDACEAE & \\
\hline Phaseolus vulgaris (L.) & 4 & Allophylus edulis (Cambess.) & 1 \\
\hline LAMIACEAE & & SOLACEAE & \\
\hline \multirow[t]{2}{*}{ Leonotis nepetifolia $(\mathrm{L})}$. & 1 & Nicandra physalodes (L.) & 4 \\
\hline & & Solanum americanum (Mill.) & 2 \\
\hline \multicolumn{4}{|l|}{ LAURACEAE } \\
\hline Nectandra lanceolata (Nees) & 1 & WINTERACEAE & \\
\hline Ocotea pulchella (Nees) & 2 & Drimys brasiliensis (Miers) & 5 \\
\hline
\end{tabular}


Durante o levantamento de plantas forrageadas por A. sexdens piriventris na Microrregião dos Campos de Lages, foram identificadas 68 espécies de plantas distribuídas em 27 famílias botânicas, dentre as utilizadas para o forrageio (Tabela 1). As famílias botânicas com maior número de espécies forrageadas foram Asterace e Poaceae, com 15 e 13 espécies respectivamente. Baccharis trimera (Asteraceae), foi à espécie vegetal que apresentou maior procura dentre as utilizadas para o forrageio por formigas A. sexdens piriventris, 10 ocasiões (Tabela 1). Segundo Martins et al. (2011), à espécie conhecida como carqueja (Baccharis trimera - Asteraceae), está amplamente distribuída na Microrregião dos Campos de Lages. Esta distribuição pode estar relacionada ao comportamento seletivo de forrageamento por formigas de A. sexdens pirivetris na região do presente estudo.

A seleção de vegetais por formigas cortadeiras de modo geral é complexa envolvendo um comportamento apurado (Ribeiro e Marinho, 2011). Segundo Viana-Bailez et al. (2016), relatam que quanto maior a distância que a formiga percorre do ninho ao recurso alimentar, mais tempo ela levará para escolher o alimento e, consequentemente, mais seletiva a formiga cortadeira será na escolha do alimento. As formigas cortadeiras podem até mesmo se especializar em cortar, por exemplo, somente gramíneas ou dicotiledôneas, inclusive serem mais seletivas fazendo o corte de determinada parte da planta, como flores e até mesmo frutos (Giesel et al., 2014). Segundo Leal et al. (2012), de modo geral, há um grande número de espécies de plantas pouco utilizadas e um pequeno número de espécies com intenso forrageamento por formigas cortadeiras.

Em estudo realizado por Costa et al. (2013), com formigas da espécie Atta cephalotes L., foi observado uma seleção de plantas dentro de um mesmo gênero, ou da própria espécie vegetal preferida para o forrageamento. Formigas cortadeiras da espécie Acromyrmex balzanis foram capazes de diferenciar a qualidade das folhas selecionadas para o forrageamento, associando a seleção da qualidade do material as necessidades de seu fungo simbionte (Andrade et al., 2020). Segundo os mesmos autores estas reações são, na verdade, reações de rejeição, aprendida pelas forrageadoras e mediada pelo fungo simbionte.

Algumas plantas são conhecidas por conter substâncias deletérias ao fungo simbionte, e este é o principal fator de direcionamento de aceite ou rejeição para atividade de forrageamento exercida pelas formigas cortadeiras (Sousa et al., 2019). Estas substâncias podem apresentar inclusive uma alta toxicidade para as formigas cortadeiras e até mesmo para o seu fungo simbionte, podendo gerar a mortalidade total do formigueiro (Araújo et al., 2018).

Podemos concluir que plantas das famílias Poaceae e Asteraceae são as mais utilizadas no forrageamento por formigas A. sexdens piriventris, a espécie Baccharis trimera (Asteraceae) é a mais forrageada, na Microrregião dos Campos de Altitude de Lages (Tabela 1).

A relação entre a distribuição da vegetação forrageada e a distância espacial dos formigueiros de A. sexdens piriventris para a Microrregião Região dos Campos de Lages, se encontram descritas nas Figuras 3. 
Figura 3. Relação entre distribuição da vegetação forrageada e a distância linear de formigueiros de Atta sexdens piriventris na Microrregião dos Campos de Lages, SC, Brasil, 2010/2011. Teste de Mantel $(r=-0,13 ; p>0,05)$ com 68 permutações entre 17 formigueiros.

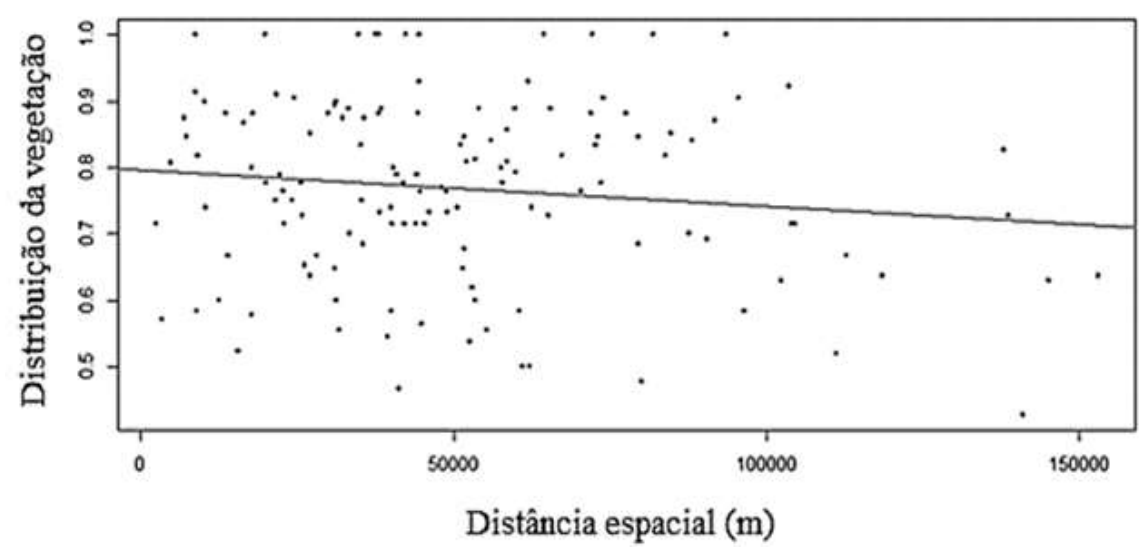

Fonte: Acervo da pesquisa.

Não houve correlação entre a distribuição da vegetação forrageada e a distância espacial dos formigueiros de $A$. sexdens piriventris (Figura 3). Deste modo, formigas cortadeiras A. sexdens piriventris forragearam as mesmas espécies vegetais nos diferentes ambientes onde foram amostrados. O índice negativo, embora não significativo (ns), demonstra uma tendência de menor preferência por espécies vegetais forrageadas distanciadas dos formigueiros de A. sexdens piriventris (Figuras 3). Blum et al. (2011) relataram que muitas espécies de plantas tropicais estão distribuídas de acordo com variações de média escala das condições ambientais. E segundo o mesmo autor pode existir microvariações das condições abióticas, que caracterizam habitats para espécies pontuais.

Desta forma pode haver uma relação entre a distribuição dos formigueiros de A. sexdens pirivetris (Figura 1), em relação à ocorrência de espécies de plantas preferidas para o forramento (Tabela 1), na Microrregião de Campos de Altitude de Lages.

Na Figura 4 está a descrição das áreas preferenciais para instalação de formigueiros por formigas das espécies $A$. sexdens piriventris para a microrregião dos campos de Lages, SC.

Figura 4. Áreas preferenciais para instalação de formigueiros de formigas Atta sexdens piriventris, localizados na Microrregião dos Campos de Lages, SC, Brasil, 2010/2011.

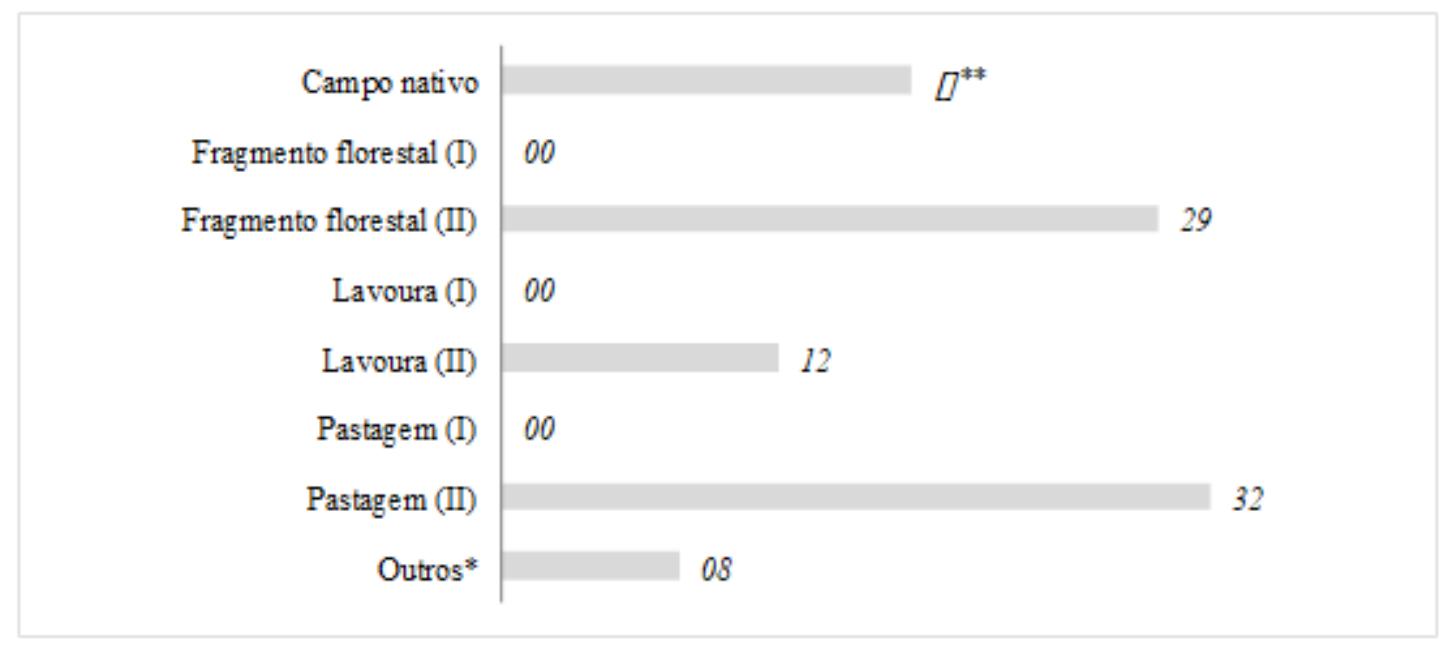

$\mathrm{I}=$ Interior e II = Borda; * Florestas plantadas, pomares e etc.; ** valores em percentual; $\mathrm{N}=17$. Fonte: Acervo da pesquisa. 
A maior parte dos formigueiros da espécie A. sexdens piriventris estavam presentes em área de borda de ambientes (73,59\%) (Figura 4). Nenhum formigueiro da espécie A. sexdens piriventris foi localizado no interior dos locais percorridos (Figura 4). O restante dos formigueiros amostrados (26,41\%) estavam presentes em áreas de campo nativo ou outras formações vegetais, como pomares e florestas plantadas, especialmente reflorestamentos de pinus e eucalipto. Segundo Giesel et al. (2014), formigas do gênero Atta preferem áreas abertas para a nidificação, preferencialmente bordas de formações florestais.

Em trabalho realizado por Vasconcelos et al. (2006), com formigas do gênero Atta, estas preferiram para nidificação as bordas de estradas. Estes autores sugerem ainda que alterações ambientais, principalmente aquelas promovidas pelo homem, tais como a abertura de estradas em áreas florestais protegidas, resultam no aumento da abundância de formigueiros do gênero Atta. Para da Silva et al., (2002) as mudanças diárias ou sazonais na atividade de forrageamento de formigas cortadeiras estão diretamente relacionadas, positivamente ou negativamente, com a temperatura e a umidade relativa do ar. Esta relação poderá ainda ser variável dentro da própria espécie, pois cada indivíduo poderá apresentar uma maior ou menor sensibilidade às variações climáticas ocorrentes em uma determinada região (Araújo et al., 2011).

\section{Considerações Finais}

As características edafoclimáticas da Microrregião dos Campos de Lages, particularizam o comportamento forrageiro e de nidificação apresentado por formigas cortadeiras A. sexdens piriventris. Plantas das famílias Poaceae e Asteraceae foram as mais utilizadas no forrageamento por formigas A. sexdens piriventris, sendo a espécie Baccharis trimera (Asteraceae) a mais forrageada. Formigueiros A. sexdens piriventris estavam presentes preferencialmente em área de borda de ambientes.

\section{Agradecimentos}

Agradecemos ao CNPq (Conselho Nacional de Desenvolvimento Científico e Tecnológico) e à FAPEU / FAPESC (Fundação de Pesquisa e Extensão Serviço Universitário / Fundação de Pesquisa e Inovação do Estado de Santa Catarina) por meio do Projeto Rede Guarani-Serra Geral n. 16.261 / 10-2 e projeto FAPESC n. 7025 / 2010-4 pelo apoio financeiro para esta pesquisa. Agradecemos também aos agricultores, alunos da UDESC (Universidade de Santa Catarina) e técnicos da EPAGRILages (Serviço de Pesquisa e Extensão Agrícola da Estação de Santa Catarina) pela valiosa ajuda durante o estudo.

\section{Referências}

Araújo, M. S., Ribeiro, M. M. R., Marinho, C. G. S., Oliveira, M. A., \& Della-Lucia, T. M. C. (2011). Fundação e estabelecimento de formigueiros. Formigascortadeiras, da Biologia ao Manejo, 173-189.

Andrade, V. S., Melo, C. R., Dantas, J. D. O., Oliveira, B. M. S., Blank, A. F., \& Bacci, L. (2020). Inseticidas botânicos de Myrcia lundiana sobre Acromyrmex balzanis. Cadernos de Agroecologia, 15(2).

Araújo, É. A. S. G. O., Fernandes, S. D. C., Roque, F., \& Delgado, M. N. (2018). Levantamento de plantas fitossanitárias utilizadas no manejo de pragas agrícolas. Revista Brasileira de Agroecologia, 13(4), 164.

Blum, C. T., Roderjan, C. V., \& Galvão, F. (2011). Composição florística e distribuição altitudinal de epífitas vasculares da Floresta Ombrófila Densa na Serra da Prata, Morretes, Paraná, Brasil. Biota Neotropica, 11(4), 141-159.

Cherrett, J. M. (1972). Some factors involved in the selection of vegetable substrate by Atta cephalotes (L.)(Hymenoptera: Formicidae) in tropical rain forest. The Journal of Animal Ecology, 647-660.

Costa, A. N. D. (2013). Efeitos diretos e indiretos das formigas cortadeiras de folha (Atta) sobre a dinâmica da vegetação em uma savana neotropical.

da Silva Araújo, M., Della Lucia, T. M. C., Lima, C. A., de Souza, D. J., \& Petternelli, E. F. (2002). Atividade de forrageamento de Acromyrmex laticeps nigrosetosus Forel (Hymenoptera, Formicidae) em povoamentos de Eucalyptus. Acta Scientiarum Maringá, 24 (5), $1321-1325$.

de Rudder, E. M. C. (2002). Guia compacto das plantas medicinais. Rideel.

Della Lucia, T. M. C., \& Souza, D. J. (2011). Importância e história de vida das formigas-cortadeiras. DELLA LUCIA, TMC Formigas-cortadeiras: da biologia ao manejo. UFV, 13-26. 
Farji-Brener, A. G., Dalton, M. C., Balza, U., Courtis, A., Lemus-Domínguez, I., Fernández-Hilario, R., \& Cáceres-Levi, D. (2018). Working in the rain? Why leaf-cutting ants stop foraging when it's raining. Insectes Sociaux, 65(2), 233-239.

Felfili, J. M., Eisenlohr, P. V., Melo, M. M. R. F., Andrade, L. A., \& Meira Neto, J. A. A. (2011). Fitossociologia no Brasil: métodos e estudos de casos. UFV, 1,556 .

Ferreira, F. T. N. (2020). Forrageamento e aprendizado espaço-temporal em formigas cortadeiras (Acromyrmex sp.) na presença de sacarose (Doctoral dissertation, Universidade de São Paulo).

Giesel, A., Boff, P., Boff, M. I. C., \& Fernandes, P. (2020). Ant nesting ecology of leaf-cutter ants in altitude natural fields, southern Brazil. Research, Society and Development, 9(9), e370997371-e370997371.

Giesel, A., Boff, P., Boff, MIC, \& Fernandes, P. (2020). Ocorrência de formigas cortadeiras em campos de altitude no sul do Brasil. Research, Society and Development, 9 (8), e839986365-e839986365.

Giesel, A. (2014). Espécies, hábitos e manejo ecológico de formigas cortadeiras dos campos de Lages.

Infante-Rodríguez, D. A., Monribot-Villanueva, J. L., Mehltreter, K., Carrión, G. L., Lachaud, J. P., Velázquez-Narváez, A. C., \& Guerrero-Analco, J. A. (2020). Características fitoquímicas das folhas determinam a taxa de forrageamento da formiga cortadeira Atta mexicana (Smith) (Hymenoptera: Formicidae). Chemoecology, 1-13.

Leal, I. R., Wirth, R., \& Tabarelli, M. (2012). Formigas-cortadeiras e a ambiguidade de suas relações com plantas. Ecologia das interações plantas-animais: uma abordagem ecológico-evolutiva. Technical Books Editora, 215-239.

Loeck, A. E., Grützmacher, D., \& Storch, G. (2001). Distribuição geográfica de Atta sexdens piriventris Santschi, 1919, nas principais regiões agropecuárias do Estado do Rio Grande do Sul. Current Agricultural Science and Technology, 7(1).

Lorenzi, H. (2008). Árvores do Brasil. Ed. Instituto plantarum, H. Lorenzi.

Lorenzi, H. (1986). Manual de identificação e controle de plantas daninhas. H. Lorenzi.

Lorenzi, H. (2008). Plantas daninhas do Brasil. Ed. Instituto plantarum, H. Lorenzi.

Maciel, M. A. F., Della Lucia, T. M. C., Araújo, M. S., \& Oliveira, M. A. (1995). Ritmo diário de atividade forrageadora da formiga cortadeira Acromyrmex subterraneus subterraneus Forel. Anais da Sociedade Entomológica do Brasil, 24(2).

Martins, D., Chaves, C. L., Bortoluzzi, R. D. C. L., \& Mantovani, A. (2011). Florística de floresta ombrófila mista altomontana e de campos em Urupema, Santa Catarina, Brasil. Revista Brasileira de Biociências, 9(2).

de Oliveira Jr, R. S., Constantin, J., \& Inoue, M. H. (2011). Biologia e manejo de plantas daninhas. Omnipax.

Reed, J., \& Cherrett, J. M. (2019). Foraging Strategies and Vegetation Exploitation in the Leaf-cutting Ant Atta cephalotes (L.) - A Preliminary Simulation Model. Applied Myrmecology: A World Perspective, 355.

Ribeiro, M. M. R., \& Marinho, C. G. S. (2011). Seleção e forrageamento em formigas-cortadeiras. Formigas-cortadeiras: da Bioecologia ao manejo. $189-203$.

Sousa, N. J., Rezende, E. H., Crespo, I., Granados, M., \& Rodrigues, C. (2019). Controle de formigas cortadeiras utilizando sementes de gergelim. enciclopédia biosfera, 16(29).

Tonhasca Jr, A., \& Bragança, M. A. L. (2000). Effect of leaf toughness on the susceptibility of the leaf-cutting ant Atta sexdens to attacks of a phorid parasitoid. Insectes Sociaux, 47(3), 220-222.

Vasconcelos, H. L., Vieira-Neto, E. H., Mundim, F. M., \& Bruna, E. M. (2006). Roads Alter the Colonization Dynamics of a Keystone Herbivore in Neotropical Savannas 1. Biotropica, 38(5), 661-665.

Viana-Bailez, A. M., \& Endringer, F. B. (2016). Plasticidade do comportamento de forrageamento em formigas cortadeiras. Oecologia Australis, 20(3), 11-19. 